\title{
ARTICLE
}

\section{Autism spectrum disorder in adults: clinical features and the role of the psychiatrist}

\author{
Jacqui Garland, Linda O'Rourke \& Dene Robertson
}

\begin{abstract}
Jacqui Garland is a clinical research fellow in neuropsychiatry at Beaumont Hospital, Dublin. Linda O'Rourke is a clinical lecturer in psychiatry with the Royal College of Surgeons in Ireland. Dene Robertson is a consultant psychiatrist in the behavioural disorders service and the Behavioural Genetics and Autism Assessment Clinic as well as the clinical lead in the neurodevelopmental disorders service with the South London and Maudsley NHS Foundation Trust. Correspondence Dr Jacqui Garland, Department of Psychiatry, Royal College of Surgeons in Ireland, Beaumont Hospital, Dublin 9, Ireland. Email: jacqui.garland@ kcl.ac.uk
\end{abstract}

\begin{abstract}
SUMMARY
Autism spectrum disorders (ASDs) are lifelong conditions. Although not all adults with ASD require psychiatric input, general adult psychiatrists increasingly find themselves responsible for the care of adults with the disorder. This may present a new and unique challenge to them. Here, we summarise the core clinical features of ASD; discuss appropriate diagnostic practice; review the principles of management; and identify key educational, social care and voluntary services for adults with ASD in the UK.

\section{DECLARATION OF INTEREST}

None.
\end{abstract}

The autism spectrum disorders (ASDs) are a family of lifelong conditions characterised by deficits in reciprocal social interaction and communication and a restricted repertoire of interests and behaviours. In recent years, it has been increasingly recognised that people with ASD have significant unmet social and healthcare needs. This recognition led to the Autism Act 2009, the first disability-specific legislation passed in the UK. The Autism Act required the Secretary of State to produce statutory guidance for local authorities and health bodies to meet the needs of adults with ASD. The subsequent 'Autism Strategy' (Department of Health 2010a) created a five-tier framework for mainstream services across the public sector outlining required improvements. These included:

- increased awareness and understanding of autism

- increased availability and consistency of diagnosis

- improved access to services and support

- increased opportunity for employment

- a more accessible service for adults.

Access to diagnostic services is important because diagnosis often leads to identification of need and to appropriate care planning. In addition, early recognition is central to preventing secondary impairments that may arise from the challenges of an undiagnosed or misdiagnosed disorder (Royal College of Psychiatrists 2006). Unfortunately, the core symptoms and signs of ASD are often not identified by health and social care professionals (Heidgerken 2005), leading to delays in obtaining a diagnosis and contributing to long-term morbidity.

\section{Epidemiology}

Autism was initially considered a rare condition (Wing 2002), possibly because of the narrowly defined, categorical approach to diagnosis autism was either present or absent. However, the classification has developed over time to establish a broader phenotype of autism known as the 'autism spectrum disorders' (ASDs). Although rates are subject to some geographical variation, ASDs are now known to occur in 1\% of the child population in the UK (Baird 2006), with a male to female ratio of approximately 3:1 (Lotter 1996; Baird 2006). The prevalence of ASD in adults in the general community has also been found to be about $1 \%$, with higher rates in men, those without educational qualifications and those living in government-financed accommodation (Brugha 2011). Unfortunately, many people with ASD remain undiagnosed into adulthood.

Studies have shown higher mortality rates among individuals with autism than the general population (Mouridsen 2008; Pickett 2011). Deaths from both 'natural' causes (including cardiovascular disease, epilepsy and infection) and 'unnatural' causes (road-traffic accident, drowning, suffocation and suicide) are overrepresented in those with ASD (Mouridsen 2008). In addition, many adults with ASD, including those of normal intelligence $(\mathrm{IQ}>70)$, are significantly disadvantaged in employment, social relationships, and quality of life (Howlin 2012).

\section{Classification}

Both childhood ('classic') autism and Asperger syndrome (the two prototypical ASDs) are defined by a 'triad of impairments' (Wing 1979): 
- qualitative impairments in reciprocal social interaction

- deficits in verbal and non-verbal communication

- restricted and repetitive behaviours and interests.

According to ICD-10, these abnormalities are pervasive across all situations (World Health Organization 1992). To satisfy ICD-10 criteria for childhood autism, impairments must manifest before the age of 3 years. About $70 \%$ of people with childhood autism also have a comorbid intellectual disability ${ }^{\dagger}$ (Baird 2006); those without an intellectual disability who meet the criteria are often described as having 'high-functioning' autism. Asperger syndrome (described in ICD-10 as 'a syndrome of uncertain nosological validity') differs from childhood autism in that there is no significant delay in language or general cognitive skills (World Health Organization 1992). While most cases of classic autism are recognised in childhood, individuals with Asperger syndrome experience significantly longer delays in obtaining a diagnosis (Howlin 1999).

Both ICD-10 and DSM-5 (American Psychiatric Association 2013) provide diagnostic criteria for ASD. Each uses its own terminology; in particular, note that pervasive developmental disorder (in ICD-10) is synonymous with ASD (Box 1). The diagnostic criteria for autism spectrum disorders have been revised in DSM-5. The four separate pervasive developmental disorders described in DSM-IV (American Psychiatric Association 2004) - autistic disorder (autism), Asperger's disorder, childhood disintegrative disorder, and pervasive developmental disorder not otherwise specified - are now subsumed under the umbrella term 'autism spectrum disorder'. In DSM-5, ASD is characterised by:

1 deficits in social communication and social interaction, and

2 restricted repetitive behaviours, interests and activities (RRBs).

Impairment in both areas is required for a diagnosis of ASD. If no RRBs are present, social communication disorder is diagnosed.

\section{Alerting characteristics of ASD in adults}

Although there is considerable interest in the use of biological measures to diagnose autism (Bloeman 2010; Ecker 2010), there are, as yet, no definitive diagnostic tests (Wing 2002). Diagnosis remains based on the presence of characteristically atypical patterns of behaviour during early development. Enduring difficulties in social relationships and social communication, or the presence of stereotyped behaviour, restricted interests and/

B0X 1 ICD-10 diagnostic criteria for autism spectrum disorders

\section{ICD-10 category F84 Pervasive developmental disorders (PDD) outlines the} following eight conditions

- Childhood autism - see Table 1. 'Highfunctioning autism' does not appear in ICD-10, and is a term reserved for people with autism but without concomitant intellectual disability (Hofvander, 2009)

- Atypical autism - differs from childhood autism in age at onset or in failure to meet diagnostic criteria in all three domains

- Rett syndrome - loss of previously gained skills in females aged 7-24 months

- Other childhood disintegrative disorder - loss of previously acquired skills in childhood not attributable to Rett syndrome
- Overactive disorder associated with mental retardation and stereotyped movements - ill-defined disorder of uncertain nosology in children with moderate to severe intellectual disability

- Asperger syndrome - a disorder of 'uncertain nosological validity'. Characterised by qualitative abnormalities in reciprocal social interaction and a restricted, repetitive repertoire of interests and activities

- Other pervasive developmental disorders

- Pervasive developmental disorder, unspecified - person fits the general description, but lack of adequate information or contradictory findings mean that criteria cannot be met

(after World Health Organization 1992)

or resistance to change should alert the clinician to the possible presence of ASD (Boxes 2 and $3)$. Below we review the assessment process and indicate how the standard psychiatric interview can be adapted to assess the symptoms and signs of ASD in adulthood.

\section{Screening tools}

Screening tools may be useful in identifying those with characteristics of possible ASD who would most benefit from further assessment.

\section{The Autism-Spectrum Quotient}

The Autism-Spectrum Quotient (AQ) is a brief, self-administered instrument which measures

B0X 2 Alerting characteristics of autism in adults

Difficulties in social relationships:

- few or no sustained relationships

- aloof, awkward interaction with others

- egocentric, with limited empathy

- poor awareness of social norm

Problems in communication:

- stilted, pedantic use of language

- monotonous voice or inappropriate volume

- non-reciprocal, one-sided interaction

- literal interpretation of what is heard

- restricted affect and limited use of gestures

- poor integration of gaze with content of speech
${ }^{\top}$ The term learning disability is used in the National Health Service.
- uncomfortable posture and body language

Absorbing and narrow interests:

- circumscribed interest of limited practical or social value

- obsessive pursuit of restricted interests

- strict daily routine and schedule

- deviation from daily structure causes distress

Onset and duration:

- onset in childhood

- lifelong condition

- pervasive across all activities of living (After Royal College of Psychiatrists 2006) 
BOX 3 Differential diagnosis of autism spectrum disorder (ASD)

\begin{tabular}{ll}
\hline Mental disorders & Genetic conditions of which ASD may be \\
- Obsessive-compulsive disorder (OCD) & a behavioural phenotype \\
- Attention-deficit hyperactivity disorder & • Velocardiofacial syndrome \\
(ADHD) & - Tuberous sclerosis \\
- Intellectual disability & - Fragile-X syndrome \\
- Schizoid personality disorder & - San Filippo syndrome \\
- Schizotypal disorder & - MECP2-related disorders (e.g. Rett syndrome) \\
- Schizophrenia & - Smith-Magenis syndrome \\
& - Adenylosuccinate lyase deficiency \\
& - Cohen syndrome \\
& - Smith-Lemli-Optiz syndrome
\end{tabular}

the degree to which adults without intellectual disability have autism spectrum traits (BaronCohen 2001). Although available in a number of forms, the most widely used is the AQ-50. It is freely available online following registration. Its authors advise that a score $>32$ on the AQ50 in a person suffering distress merits referral for a full diagnostic assessment (Baron-Cohen 2001). However, there are people who score lower than the suggested threshold of 32, but for whom clinical suspicion dictates the need for further evaluation. In a clinical sample of adults referred for assessment for Asperger syndrome, a cut-off score of 26 differentiated well between those who received a diagnosis of Asperger syndrome and those who did not (Woodbury-Smith 2005).

Another form of the instrument, the AQ-10, is identified in NICE clinical guideline CG142 as suitable for screening in primary, social care and non-specialist settings (National Institute for Health and Clinical Excellence 2012). A score of 6 supports referral for specialist assessment (National Institute for Health Research 2012). It should be noted that people with limited insight into their difficulties might not endorse impairments on self-report measures. In such individuals the AQ may not always provide a valid measure of ASD-related impairment, so caution should be exercised in using the $\mathrm{AQ}$ alone to screen for the presence of ASD (Bishop 2012).

\section{Adapting the standard psychiatric assessment}

Suspicion about the presence of ASD may arise during a general assessment, in which case the interview may be adapted to include careful consideration of key domains, as follows.

History of presenting complaint

What is the nature of the patient's difficulties - are there difficulties with reciprocal communication, social interaction or restricted and repetitive patterns of behaviour and interest? Are they lifelong and pervasive?

\section{Psychiatric history}

Has there been contact with child, adult or learning disability services? What were the diagnoses? Was there treatment for ASD or possible comorbid conditions?

\section{Family history}

Is there a history of neurodevelopmental disorder among first- or second-degree relatives?

\section{Medical history}

Is there a history of epilepsy, visual or auditory impairment? Is there a history of sleep or gastrointestinal problems? Does the patient suffer from a physical condition of which ASD may be a behavioural phenotype?

\section{Developmental history}

Was there abnormality in general cognitive, linguistic, social or motor milestones?

This is a critical area of enquiry. A collateral history focusing on early childhood development should be obtained from a parent or caregiver if at all possible. This is used to establish both the presence of atypical social behaviour during childhood, and its neurodevelopmental nature. The age at onset of impairment in the areas of language, relationships and behaviour should be carefully examined. An inventory of the age and pattern of acquisition of developmental milestones should be taken.

Motor milestones include age at walking independently (less than 18 months being within normal limits). The age at which the individual first used single words and phrases should be noted (single words normally achieved by 24 months and phrase speech by 33 months), as the presence of significant language delay is consistent with childhood autism but excludes a diagnosis of Asperger syndrome.

Additional childhood clues suggestive of an ASD include a lack of appropriate use of gestures such as pointing to express interest, difficulty in engaging in a reciprocal conversation and use of peculiar 'non-words' or idiosyncratic language. There may have been a tendency to say things in a ritualised way. There may have been unusual intonation, volume, rate or rhythm of speech.

Enquiry into the pattern and quality of social development and play may reveal other behaviour patterns consistent with an ASD. For example, as a child, the person may have had difficulty playing 
cooperatively with others and establishing friendships independently. Play may have involved the sensory manipulation of objects rather than socially oriented imaginative play with peers. The child may have displayed a tendency to ignore others, may not have smiled socially and may have displayed an aversion to touch.

\section{Personal and social history}

Are there persistent difficulties in initiating and maintaining social relationships? Has the person experienced bullying in school or in the workplace? Have difficulties been accentuated at transitions to the socially demanding settings of secondary school or higher education? Are there problems with educational attainment or obtaining and sustaining employment? What are the person's living circumstances and level of adaptive functioning? Are they living independently or reliant on family members or carers?

\section{Mental state examination}

Mental state examination may expose deficits in the subtleties of social engagement and communication.

An adult with ASD may appear aloof or awkward and may have difficulty engaging in a reciprocal manner during the interview. Conversational interchange may not be initiated or sustained. Speech may be monotonous and stilted, with a lack of cadence. Echolalia may be observed (the vocalisations of the interviewer are repeated). Neologisms and idiosyncratic language may be used. Thinking style may be inflexible or concrete. Narrow, circumscribed interests may dominate thought content. Someone with an ASD may not spontaneously share personal information.

Eye contact may be avoidant or inappropriately fixed. Facial expressions may be restricted or abnormally exaggerated. A lack of use of descriptive, conventional or informative gestures may be observed. Repetitive or stereotyped motor mannerisms such as hand- or finger-twisting may be noted. The individual may display unusual sensory-seeking behaviours, such as sniffing or touching, or sensory avoidance.

On assessment of mood, a person with autism may have difficulty identifying and expressing their own emotions.

\section{Psychiatric assessment when ASD is suspected}

The assessment of patients with suspected ASD requires particular knowledge and skills (Box 4). The interviewer should use low-arousal questioning in a distraction-free environment and take care to avoid triggers for fear or anxiety. A discussion with a family member or carer in advance of the interview may elucidate how the person best communicates and what factors may help them feel more comfortable during the assessment. The purpose of the assessment should be discussed with the patient from the outset. Many features of ASDs may be subtle and difficult to confidently identify, so enough time should be set aside and more than one interview may be necessary. The assessing clinician should avoid using ambiguous language and complex questions with multiple clauses.

The Royal College of Psychiatrists provides a helpful diagnostic interview guide for clinicians which can be downloaded for free (Berney 2011). Table 1 contains a guide to linking ASD signs and symptoms to ICD-10 diagnostic criteria.

\section{Special tests/formal assessment tools}

Although formal assessment always includes a full clinical and developmental history, in anything other than clear-cut cases it is appropriate to use one of a number of special tests to support a diagnosis of ASD. Two widely used assessment instruments are the Autism Diagnostic InterviewRevised (ADI-R; Lord 1994) and the Autism Diagnostic Observation Schedule-Generic (ADOS-G; Lord 2000). The use of such tools can be particularly helpful in adding structure to the assessment of complex or marginal cases.

\section{The Autism Diagnostic Interview-Revised (ADI-R)}

This is a standardised, semi-structured interview conducted with a parent or caregiver. It includes

BOX 4 Desirable knowledge, skills and experience in assessing for autism spectrum disorders
Knowledge of:
- aetiology
- development
- clinical features
- associated core deficits
Skills to:
- recognise the alerting characteristics
- take an adequate clinical and developmental history
- relate to a person with ASD
- relate to a family affected by ASD
Experience in:
- interview and assessment of patients with ASD
- treatment of ASD

(Adapted from Royal College of Psychiatrists 2006) 


\begin{tabular}{|c|c|c|}
\hline Domain & ICD diagnostic criteria & Clues from history/examination \\
\hline $\begin{array}{l}\text { Development - } \\
\text { required only for a } \\
\text { diagnosis of childhood } \\
\text { autism }\end{array}$ & $\begin{array}{l}\text { Abnormal or impaired development before the age of } 3 \text { years in at } \\
\text { least one of the following: } \\
\text { (a) receptive or expressive language in social communication; } \\
\text { (b) development of selective social attachments or reciprocal social } \\
\text { interaction; } \\
\text { (c) functional or symbolic play }\end{array}$ & $\begin{array}{l}\text { Clear delay in use of speech to communicate } \\
\text { No single words by } 2 \text { years of age } \\
\text { No phrase speech by } 3 \text { years of age }\end{array}$ \\
\hline Social & $\begin{array}{l}\text { Qualitative abnormalities in at least two of the following: } \\
\text { (a) failure to adequately use eye-to-eye gaze, facial expression, } \\
\text { body posture and gesture to regulate social interaction } \\
\text { (b) failure to develop peer relationships that involve a mutual } \\
\text { sharing of interests, activities and emotions } \\
\text { (c) lack of socioemotional reciprocity or lack of modulation of } \\
\text { behaviour according to social context or a weak integration of } \\
\text { social, emotional and communicative behaviours } \\
\text { (d) lack of spontaneous seeking to share enjoyment, interests or } \\
\text { achievements with other people }\end{array}$ & $\begin{array}{l}\text { Lack of direct eye contact and poor modulation of eye contact to } \\
\text { regulate social interactions } \\
\text { Restricted or inappropriate range of facial expression } \\
\text { Lack of emotional expression } \\
\text { Absence of close sharing friendships or relationships } \\
\text { Dislike of physical contact and impaired ability to comfort others } \\
\text { Lack of social chit-chat or 'small talk' when in company } \\
\text { Abnormal play - dislike of shared play, lack of symbolic use of toys } \\
\text { in childhood }\end{array}$ \\
\hline Communication & $\begin{array}{l}\text { Qualitative abnormalities in at least one of the following: } \\
\text { (a) delay or total lack of spoken language, not accompanied by an } \\
\text { attempt to compensate through the use of gesture or mime } \\
\text { (childhood autism only) } \\
\text { (b) relative failure to initiate or sustain conversational interchange } \\
\text { with reciprocal responsiveness } \\
\text { (c) stereotyped and repetitive use of language or idiosyncratic use } \\
\text { of words or phrases } \\
\text { (d) lack of varied, spontaneous make-believe or social imitative play }\end{array}$ & $\begin{array}{l}\text { Poor flexibility in language expression } \\
\text { Lack of descriptive, conventional or informative gestures } \\
\text { Lack of creativity and fantasy in thought processes } \\
\text { Lack of emotional response to another's verbal and non-verbal } \\
\text { overtures } \\
\text { Impaired use of cadence of speech to reflect communicative intent } \\
\text { Use of echolalia, neologisms and pronoun reversal } \\
\text { Lack of spontaneous conversation or sharing of personal information }\end{array}$ \\
\hline Behaviour & $\begin{array}{l}\text { Restricted, repetitive and stereotyped patterns of behaviour, } \\
\text { interests and activities in at least one of the following: } \\
\text { (a) an encompassing preoccupation with at least one stereotyped } \\
\text { and restricted interest which is abnormal in content or focus, } \\
\text { or at least one interest which is abnormal in intensity and } \\
\text { circumscribed nature } \\
\text { (b) apparently compulsive adherence to specific, non-functional } \\
\text { routines or rituals } \\
\text { (c) stereotyped and repetitive motor mannerisms such as hand/ } \\
\text { finger flapping or twisting or complex whole-body movements } \\
\text { (d) preoccupations with part-objects or non-functional elements of } \\
\text { play materials }\end{array}$ & $\begin{array}{l}\text { Imposition of non-functional rigidity and routine on everyday and } \\
\text { novel experiences } \\
\text { Resistance to change in routine or environment } \\
\text { Abnormal play - preoccupation with parts of objects } \\
\text { Lack of spontaneity, initiative and creativity } \\
\text { Lack of spontaneous imitation/mirroring of others } \\
\text { Unusual sensory-seeking or sensory-avoidance behaviours } \\
\text { Increased sensitivity to noise } \\
\text { Temper/outbursts } \\
\text { Aggression } \\
\text { Self-injury } \\
\text { Anxiety symptoms } \\
\text { Difficulties in the educational or occupational environment } \\
\text { Sleep difficulties } \\
\text { Eating disturbances }\end{array}$ \\
\hline
\end{tabular}

Sources: Lord 1989, 1994; World Health Organization 1992; Fitzgerald 2001.

93 questions on early development, language, social interest, play and behaviours relevant to the person's social interaction, communication and patterns of behaviour. Coding produces a score for each domain, and cut-off scores allow for diagnosis (Lord 1994). Use of the ADI-R requires specialist training. Some services identify a single clinician to develop expertise in the use of an assessment tool such as the ADI-R.

\section{The Autism Diagnostic Observation Schedule-} Generic (ADOS-G)

This is a semi-structured, standardised assessment of communication, social interaction and imaginative use of materials. It consists of four modules, each designed for different age groups and language skills. Module 4 is used for adults and high-functioning children. Participant behaviour is recorded and rated, and cut-off scores allow for diagnosis (Lord 1989, 2000). Training is available but not mandatory, as clinical experience is sufficient for effective use. Purchase of materials and coding booklets is required.

\section{Comorbid disorders}

Assessment for comorbid disorders is a crucial part of a comprehensive ASD assessment. Comorbidity occurs in up to $70 \%$ of those with ASD and can have a greater effect on outcome and functioning than an individual's core symptoms (Levy 2009). Detection of comorbid disorder involves possession of the skills to differentiate between an unusual but recognised feature of ASD and a truly comorbid condition. The standard diagnostic classification of comorbid mental disorder using ICD-10 or DSM-IV criteria applies to the ASD population. 
However, in those with an intellectual disability alternative criteria may be utilised, for example the DC-LD (Royal College of Psychiatrists 2001).

\section{Depressive disorder}

Depressive disorder is probably the most frequently occurring comorbid psychiatric illness in ASD (Ghaziuddin 2002), and often co-occurs with anxiety disorder. However, professionals may fail to identify mood disorder because people with ASD can have great difficulty identifying their feelings (as a result of alexithymia) and in reporting them (owing to deficits in social communication). Therefore, it may be necessary to place increased emphasis on inferring mental state change from any changes in functioning or behaviour. It is common experience that people with ASD are better at completing forms than reporting feelings, so self-report scales should be made available where possible.

\section{Anxiety disorder}

Rates of anxiety disorder are high in people with ASD (including specific phobia, agoraphobia, generalised anxiety disorder and obsessivecompulsive disorder). Individuals who are aware of their social difficulties may experience anxiety in expectation of negative social feedback. This leads to avoidance of peers and contributes to social loneliness (White 2009). While social anxiety, lack of enjoyment, social avoidance and preference of solitude can be overlapping features with social anxiety disorder, it is important for the psychiatrist to discriminate between disorders (White 2012) in order to prescribe appropriate treatment. This can be achieved by careful examination of the longitudinal history of social and communication impairments using a focused developmental history, keeping in mind that the typical age at onset of social anxiety disorder is mid-adolescence (Schneider 1992).

\section{Obsessive-compulsive disorder}

Although autistic traits are common in adults with obsessive-compulsive disorder (OCD) (Bejerot 2001) and obsessional traits are common in those with ASD, repetitive behaviours inherent in ASD should be clearly distinguished from OCD. Careful examination of repetitive thoughts and behaviours using specific and concrete questioning is necessary to distinguish between ASD and OCD. Critically, in OCD obsessional thoughts are almost invariably ego-dystonic and unsuccessfully resisted (World Health Organization 1992) - the only real exceptions being for very long-standing difficulties. Individuals with ASD are less likely to experience aggressive, contamination, sexual, religious, symmetry or somatic thoughts, but are more likely to experience repetitive behaviours including imposing order, hoarding, touching, tapping, rubbing and self-mutilating. Compulsions in OCD are more typically cleaning, checking and counting (McDougle 1995).

\section{Schizophrenia}

The term 'autism' was first used by Paul Eugen Bleuler in 1910 to describe states of withdrawal in people with schizophrenia. Consequently, it is no surprise that impairments in social relatedness and language are shared features of ASDs and schizophrenia (Sheitman 2004), and that adolescents with schizophrenia commonly exhibit autistic traits (Waris 2013). This phenomenological overlap is likely to partly underlie the wide variability in the reported rates of schizophrenia in people with ASD (Skokauskas 2010); for example, a study of adults with ASD referred to psychiatric services found high rates of lifetime (13\%) and current (8\%) psychosis (Joshi 2013), in contrast to rates of $0.6 \%$ in a population of adults with autism (Volkmar 1998). Moreover, some people with ASD experience persecutory ideas of reference - likely to be in part consequent on deficits in theory of mind - that may be mistaken for psychotic symptoms. Therefore, both differentiating between schizophrenia and ASD, and making a diagnosis of schizophrenia in a person with an ASD, depend critically on the quality of the developmental history (an ASD is not present if characteristic features were not present during early childhood), and establishing the phenomenology of possible psychotic symptoms in detail (the diagnosis of a psychotic disorder is appropriate in a person with an ASD if positive psychotic symptoms are clearly present).

\section{Eating disorders}

Rates of ASD may be higher among patients with eating disorders than in the general population (Treasure 2010), with ASD affecting nearly 20\% of adults with anorexia nervosa (Wentz 2005). Adolescent girls with Asperger syndrome have more eating problems than their typically developing peers (Kalyva 2009). In those with severe and enduring eating disorders an unrecognised ASD may impede and complicate treatment, and worsen prognosis (Wentz 2005). Identification of ASDs in people with eating disorders is important, as treatment modalities may differ depending on whether an ASD is or is not present - for example, psychodynamic treatments are unlikely to be appropriate for patients with ASD. 


\section{Substance misuse}

Adults with ASD are at lower risk of cigarette smoking and alcohol misuse than the general population (Bejerot 2003; Abdallah 2011). Lowered rates may be due to a variety of factors associated with ASD, such as lack of a peer group that misuses substances, harm avoidance and low risk-taking behaviour (Santosh 2006). However, among all adults referred to psychiatric services, rates of substance use disorders in those with ASD are comparable to rates observed in those without ASD (Sizoo 2010; Joshi 2013). Individuals with ASD and comorbid attention-deficit hyperactivity disorder (ADHD) are more likely to misuse substances than those with ASD alone (Lugnegard 2011). Adults with ASD who do misuse substances experience higher levels of substance-related disability (Sizoo 2010). Other risk factors for substance misuse in adults with ASD include regular smoking early in life, family adverse events and parental history of substance misuse (Sizoo 2010). Substance misuse is less common among adults who have both intellectual disability and autism than in adults with intellectual disability alone (Chaplin 2011).

\section{Other neurodevelopmental disorder}

Autism and intellectual disability co-occur at very high rates (Rutter 1978). Social and adaptive skills deficits, stereotyped behaviours and challenging behaviours occur in people with intellectual disability (Matson 2009) and this may complicate the diagnosis of ASD. People with intellectual disability and comorbid ASD are particularly disadvantaged, with poorer social skills (Smith 2010) and more psychiatric comorbidity than those with intellectual disability alone (Matson 2009). Moreover, adulthood outcomes for those with intellectual disability and ASD are worse than for those with ASD alone (Howlin 2004).

Although ICD-10 diagnostic criteria do not support the co-diagnosis of ADHD and ASD, Hofvander et al (2009) reported ADHD symptoms in around $43 \%$ of adults with ASD, and this finding is now well replicated. This is of critical importance, because failure to recognise symptoms and signs of ADHD in people with ASD leads to failure to prescribe appropriate treatment and to increased (reversible) morbidity.

Tic disorders are overrepresented in people with ASD. They have been reported to be more common in Asperger syndrome than in autism (Gillberg 2000). Tourette syndrome affects $4-8 \%$ of young people with ASD in the UK (Baron-Cohen 1999).

Tics should be differentiated from the stereotypies and repetitive behaviours of ASD and the compulsive behaviour of OCD.

\section{Physical assessment}

A systematic medical history and physical examination are essential for all patients with ASD (Rutter 1994). Rates of medical illness are estimated at 10-20\% (Rutter 1994; Oliveira 2007). A number of medical conditions are associated with ASD, including neurological, gastrointestinal, nutritional and sleep disorders. Clinicians should be aware that some individuals with ASD are insensitive to cold and pain (Bailey 1998), which may lead to a reduction in symptomreporting, while deficits in communication can make diagnosis by clinical interview difficult (Mouridsen 2008).

\section{Epilepsy}

Epilepsy is the most common neurological condition associated with autism and contributes to increased morbidity and mortality (Tuchman 2011). The prevalence of epilepsy in children with autism has been reported to range from $5 \%$ to 38\% (Levisohn 2007). This childhood epilepsy is particularly persistent into adulthood, with remission in only 16\% of cases (Danielsson 2005). It is no surprise that the presence of comorbid intellectual disability significantly increases therisk of epilepsy (Tuchman 2011). Magnetic resonance imaging (MRI) and electroencephalography (EEG) remain useful in the assessment of significant neurological comorbidity in the presence of focal neurological signs or seizures.

\section{Gastrointestinal disorder}

It has been reported that there is an association between gastrointestinal symptoms such as diarrhoea, constipation, bloating and abdominal pain and ASD (Molloy 2003). People with ASD who are experiencing abdominal pain may display unusual behaviours such as frequent throat clearing, screaming, grimacing, sleep disturbances or self-injurious behaviour (Venkat 2012). Additionally, individuals with ASD may display stereotyped behaviours around food and diet. The exclusion of certain foods (for which there is no significant current evidence in the management of ASD) or eating at particular times may risk the development of nutritional deficiencies (Venkat 2012).

\section{Sleep disorders}

Sleep problems, including difficulties with initial and middle insomnia, and shorter duration of sleep, are associated with ASD (Krakowiak 2008). The aetiology is likely to be multifactorial, and may include ASD-related alterations to brain structure and function, increased rates of mood and anxiety 
disorders (which are themselves associated with sleep abnormality), and the avoidance of social interaction. Where psychotropic medication has been prescribed care should be taken to assess for an association between medication side-effects and sleep disturbance.

\section{Genetic tests}

The heritability of ASD is thought to be about 80\% (Lichtenstein 2010), but genetic contributions to the aetiology of ASD are complex, and the majority of individuals with autism do not have a demonstrable genetic disorder. However, autism is associated with a number of single-gene and chromosomal disorders, including tuberous sclerosis, fragile-X syndrome, Rett syndrome, Angelman syndrome, velocardiofacial syndrome and Down syndrome (Caglayan 2010). Further, recent evidence suggests that there are increased rates of copy number variations (CNVs: small regions of duplicated or deleted DNA that may involve one or more genes) in groups of people with autism (Grayton 2012), although it is rarely clear in an individual how or whether these relate to phenotype. Therefore, genetic testing is not appropriate on a routine basis, but it is appropriate in two situations.

The first is if the patient has dysmorphic features or other suggestive pathology. For example, tuberous sclerosis is associated with facial angiofibromas and hypomelanotic macules, and fragile-X syndrome with long ears and face, and a high, arched palate. Some hamartomatous disorders present with neurobehavioural features resembling ASD, and testing for the PTEN gene may be considered for patients with autistic behaviour and extreme macrocephaly (i.e. head circumference greater than +4 s.d.) (Butler 2005).

The second is if there are other reasons for suspicion of genetic disorder. For example, genetic testing for Rett syndrome may be indicated for girls displaying developmental regression and autistic behaviours.

\section{Functional level}

Adaptive skills are specific skills required for everyday independent living, including those related to personal care, home living, work, leisure and community integration. Individuals with ASD show deficits in 'real life' social and communication skills required for successful independent functioning (Klin 2007). Consequently, they are more likely to be reliant on others for support in living, employment and relationships (Howlin 2004; Eaves 2008). It is important to take an inventory of adaptive skills during the clinical assessment and from a collateral informant where available. Considerations can then be included in the individual's care plan.

\section{Risk}

The assessment and management of risk is an integral part of the care of any patient. As with other mental health problems, enquiry should be made about risk of self-harm, suicide, self-neglect, exploitation and bullying by others, harm to others, and illegal activity. Risk of self-harm should be assessed in the knowledge that patients with ASD (particularly those with comorbid depression and/ or anxiety) may have difficulty reporting feelings or seeking help appropriately.

\section{Challenging behaviour}

Childhood autism is a risk factor for challenging behaviours that may pose risks to the individual, their carers and others. Relevant behaviours may include aggression, pica, head-banging, finger-/knuckle-/wrist-biting, chin-knocking, cheek-smacking, eye-poking, hair-tearing and clawing (Gillberg 2000). Such behaviours are a barrier to socialisation, the maintenance of stable residence, and employment (Graetz 2010). Although more common in people with ASD and intellectual disability, such difficulties also occur in people with ASD without intellectual disability, particularly those with comorbid psychopathology (Matson 2007).

Challenging behaviours may emerge as the result of a number of factors, including a change in routine, sensory over- or understimulation, communication breakdown, comorbid psychiatric illness, physical symptoms (pain, infection, constipation, seizure disorder), and other environmental or psychological factors. The assessment of challenging behaviour usually involves applied behavioural analysis as well as ensuring that reversible mental or physical health difficulties have been treated (see 'Care planning', below).

\section{Socially inappropriate behaviour}

People with ASD may display socially inappropriate behaviours such as social disinhibition, unusual facial expressions, uncoordinated eye contact, touching, sniffing and tasting (Lord 1994), which may engender teasing and bullying by others. Deficits in integrating the spoken word with non-verbal communication (Kana 2012), poor recognition and interpretation of facial expressions, low self-esteem, inability to resolve conflict and poor recognition of likely consequences can contribute to social isolation, manipulation, exploitation and maltreatment of the individual. 
Use of adult safeguarding legislation (Mandelstam 2011) should be considered if an individual with ASD is noted to be vulnerable.

Most persons with ASD are law abiding and rarely engage in illegal behaviour (Browning 2011). Early research implied that the prevalence of ASD among the prison population was higher than in the general population, at 1.5\% (Scragg 1994), but this has been refuted in recent literature. Those with ASD who do find themselves within the criminal justice system struggle to negotiate the court system (Allen 2008). Juries may also misinterpret their lack of social and communication skills as cold, calculating or remorseless personality traits (Browning 2011).

\section{Education and employment}

Consideration of need in the areas of education and employment should also form part of a comprehensive assessment. Youths with ASD are uniquely disadvantaged. They have the highest risk of complete disassociation from third-level education and employment (Shattuck 2012). A general population survey of ASD in adults found that the odds of being unemployed were not significantly increased (Brugha 2011). However, follow-up studies of adults diagnosed in childhood demonstrate that only a minority are working and living independently (Howlin 2004). This may relate to poor academic achievement - the majority leave school without any formal qualification (Howlin 2004). In addition, the sociocommunication demands of interviews and of the workplace make securing and maintaining employment challenging (Higgins 2008). Individuals who are employed tend to have relatively poorly paid positions (Howlin 2004).

\section{Care planning}

Adults with ASD share a triad of impairments, but treatment and support needs vary considerably. Therefore, diagnosis is only part of the information that is necessary for a comprehensive assessment and for individualised care planning. The needs of a person with ASD are likely to vary widely across a number of dimensions, including age, autistic symptoms, intellectual capacity, presence or absence of challenging behaviour, comorbid psychiatric illness, functional level, environmental circumstances and issues related to family and carer support.

The majority of adults with ASD have aspirations for life that do not differ significantly from those of the rest of society, including for friendship, employment and independence (Bancroft 2012). All agencies with which adults with ASD might come into contact should be able to identify local social care, housing, educational, employment and benefits services for them - whether or not the person has additional mental health needs.

Unfortunately, nearly two-thirds of adults with ASD report that they have never had a community care assessment and do not have enough support to meet their day-to-day needs (Bancroft 2012). Anybody who has or appears to have support needs has a right to a community care assessment under guidance issued by the Department of Health to local councils (Department of Health 2010b). Assessments are carried out by Social Services, although in practice only 'severe' or 'critical' needs are likely to be met. Carers have a right to their own assessment, which may be undertaken separately from the assessment of the person for whom they are caring.

When mental health difficulties also exist, the expertise of the wider multidisciplinary team is likely to be engaged. Both NICE (National Institute for Health and Clinical Excellence 2012) and the Social Care Institute for Excellence (2011a,b) have published useful guidance, and the National Autistic Society (www.autism.org.uk) is a helpful general resource.

\section{Psychoeducation and information-sharing}

All patients should be given clear, accurate information regarding $\mathrm{ASD}$, and afforded the opportunity to ask questions of the diagnosing team. Good-quality written information should also be provided. It is good practice for patients to receive copies of letters sent to the professionals involved in their care. Patients and their families should be advised of support agencies, local charities and the role of disability legislation such as the Autism Act 2009. People with autism and their carers may be eligible for a range of financial supports and services.

\section{Therapeutic options}

Social and psychological interventions are the main therapeutic approach for autism in adults. Medication may be used in certain circumstances.

\section{Behavioural management}

Despite a limited evidence base, adaptive-skills training which is structured, predictable and consistent may be beneficial for adults with autism who require assistance with developing dailyliving skills (National Institute for Health and Clinical Excellence 2012). The NICE guidance recommends that behavioural interventions for challenging behaviour in adults should also be considered. The target behaviour should be 
clearly identified and applied behavioural analysis (functional analysis) undertaken to establish the behaviour's antecedents and consequences. Antecedents may include physical ill health and psychiatric or psychological morbidity, as well as environmental factors. Analysis allows modification of precipitating and maintaining factors. Targeted interventions can include a clear reinforcement schedule contingent on demonstrated desired behaviour. 'Before' and 'after' measures are crucial to ensure that the target behaviour is modified. They also allow upgrading of the behavioural programme should it no longer provide the necessary reinforcement.

It should be noted that the NICE guidelines do not recommend behavioural therapy for core communication impairments in adults with autism, owing to a lack of an evidence base. The guidelines explicitly state that facilitated communication for adults with autism is not recommended and should not be provided.

\section{Cognitive-behavioural therapy}

The NICE guidelines recommend that, for adults with autism and comorbid mental health problems, psychosocial interventions informed by existing guidance for the specific comorbid disorder should be offered (National Institute for Health and Clinical Excellence 2012). Cognitive-behavioural therapy (CBT) is an evidence-based psychological intervention for the treatment of a wide variety of mental health problems, including depression and anxiety disorders, and is thus an appropriate choice for the management of relevant comorbid disorders in ASD.

A key advantage of CBT over other psychological interventions is its inherent structure. This may complement the cognitive rigidity experienced by many people with ASD. However, the impairments associated with ASD also present challenges to performing CBT in a conventional manner. Cognitive-behavioural therapy is a collaborative process and the social, communication and behavioural difficulties of ASD can make rapportbuilding and problem identification difficult. Discussing the person's special interest may lend to the building of rapport. It may also be useful to involve a family member, carer or support worker who may attenuate the patient's anxiety.

More time may be required to compensate for attention-related difficulties or slower information processing. Regular breaks or shorter sessions may be helpful. Because people with autism may have difficulties in discriminating between thoughts, feelings and behaviours, there may need to be increased emphasis on the behavioural rather than cognitive aspects of CBT. A person with autism may benefit from visual/pictorial rather than verbal material (e.g., showing a diagram of a ladder to explain graded exposure), a diagrammatic rather than verbal formulation, and the provision of written information, visual worksheets and images. It is essential to avoid ambiguous language in the delivery of CBT - or in any aspect of engagement with people with ASD.

\section{Psychotropic drugs}

No medications are licensed for the core symptoms of ASD, but psychotropic medication is frequently prescribed in the ASD population (Tsiouris 2013). The NICE guidance states that pharmacological interventions are appropriate only for the treatment of comorbid psychiatric disorders (National Institute for Health and Clinical Excellence 2012). Nevertheless, failure to identify and treat comorbid conditions (see above) may be as a great a problem as inappropriate treatment. If used, psychotropic medication should be initiated at a low dose and titrated slowly, because adults with autism may have enhanced sensitivity to side-effects. For instance, evidence suggests that people with comorbid ASD and schizophrenia more frequently experience motor side-effects of antipsychotics than those with schizophrenia alone (Raja 2010).

\section{Antipsychotic drugs}

Antipsychotics are widely used in the management of challenging behaviour in people with intellectual disability and/or ASD. However, such use exposes the recipient to risk of significant harm, and is often inappropriate. In the context of ASD, risperidone has been shown to have significant beneficial effects on aggression, irritability and repetitive behaviour (McDougle 1998; Hellings 2006), and the results of two randomised controlled trials in children and youths suggest that aripiprazole may be effective in decreasing irritability, hyperactivity and repetitive behaviours (Marcus 2009; Owen 2009). Nevertheless, the evidence base for adults remains thin, and atypical antipsychotics should be considered for the management of challenging behaviour in adults with autism only when psychosocial interventions have failed (National Institute for Health and Clinical Excellence 2012).

\section{Antidepressant drugs}

Antidepressants, in particular selective serotonin reuptake inhibitors, are also commonly prescribed to adults with ASD (Esbensen 2009), especially for the treatment of comorbid anxiety and mood disorder. A small placebo-controlled trial of fluvoxamine in adults with ASD found effects on 
core autistic symptoms, repetitive behaviour and aggression (McDougle 1996); however, as with antipsychotics, the evidence base for beneficial effects in the absence of comorbid psychiatric illness is poor.

\section{Stimulant drugs}

Methylphenidate has been shown to reduce hyperactivity in children with ASD (Research Units on Paediatric Psychopharmacology 2005). Two placebo-controlled trials have also found atomoxetine to be moderately effective and generally well tolerated in treating hyperactivity in this population (Arnold 2006; Hafterkamp 2012).

\section{Educational support}

The number of university students with a diagnosis of autism increased more than fourfold between 2003 and 2008 (National Audit Office 2009). The Special Educational Needs and Disability Act 2001 (SENDA) establishes legal rights for students with disabilities in education, and universities and colleges have a duty to make necessary 'reasonable' adjustments to help a disabled student access higher education. Students with ASD who are taking a higher education course may be eligible for a disabled students' allowance to assist with educational costs. In addition, the National Autistic Society offers student support for people with ASD who are in further and higher education.

BOX 5 Resources for adults with autism spectrum disorders, their carers and professionals

National Autistic Society (www.autism. org.uk) - the UK's leading autism charity, providing individuals, families and professionals with valuable information and support in relation to the diagnosis of autism, benefits, accommodation, advocacy and social groups. Key services include:

- Autism Helpline (www.autism.org.uk/ helpline; tel. 0808800 4104, 10 a.m. to 4 p.m. Monday to Friday, free from UK landlines and most mobile phones) resources include introductory packs, information sheets, advice regarding benefits, Social Services and a telephone interpretation service for callers whose first language is not English

- Autism Services Directory (www.autism. org.uk/directory) - a comprehensive directory of services and supports for people with ASD in the UK
This service provides support in the areas of time management, organisational and social skills, and dealing with the transition to university.

\section{Employment interventions}

Employment improves self-esteem and social contact, leads to the maintenance and acquisition of skills, and benefits everyone financially. This is no less the case for people with ASD, who should be supported in developing work-related skills and accessing employment. 'Prospects' is a specialised employment and training agency run by the National Autistic Society that offers advice and support to people with ASD who wish to work (Box 5). Employers may also benefit from assistance from Prospects in relation to recruitment, training and the retention of staff.

\section{Benefits and allowances}

Adults with ASD are often less knowledgeable about important aspects of their financial circumstances and are less likely to know whether they are receiving state benefits (Brugha 2011). Navigating the benefits system can be complicated; this may result in people not claiming the benefits to which they are entitled unless supported by someone with knowledge of ASD. The National Autistic Society website has a help page and upto-date information pack regarding benefits and community care.

\section{Social skills training}

Social anxiety and poor social skills often interact to compromise the social functioning of people with ASD. Therefore, treatments for social anxiety (see section above) and social skills training should both be made available when appropriate. Social skills training should preferably take place in a smallgroup setting with a focus on improving social interaction. However, individual training may be more appropriate for someone who has found prior group experiences difficult or impossible and is reluctant or unable to engage with a group. Nonverbal skills training develops understanding of and practice in appropriate eye contact, personal distance, body language and facial expression through the processes of modelling and feedback. Conversation skills training can include how to engage in 'small talk' and turn-taking.

\section{Leisure activities}

Adults with ASD living in the community are often socially isolated. Therapeutic interventions involving structured leisure activities have a positive influence on quality of life and stress levels (Garcia-Villamisar 2010) and should be considered 
for adults with autism who have limited social contacts (National Institute for Health and Clinical Excellence 2012). Activities may be group-based, structured and supported by a facilitator who is knowledgeable about autism. Such groups might include exercise, games, social outings, reading and music. The group setting allows for development of social skills and an increased awareness of the condition among others. For those unable to engage in group activities, the National Autistic Society runs a befriending and mentoring scheme. Befrienders spend time socialising on a one-to-one basis with people with autism and support them in engaging with community activities. Mentors help individuals learn new skills and achieve personal goals such as travelling more independently.

\section{Support for families}

Caring for a person with ASD can be associated with significant stress levels in parents and increased need for both practical and emotional family support (Hall 2011). Siblings, parents and carers of people with autism can also apply to the National Autistic Society for a befriender. Box 5 lists some of the resources available in the UK and Ireland for people with ASD and their carers.

\section{Recommendations}

The ASDs are common, lifelong neurodevelopmental conditions but a significant proportion of people remain undiagnosed into adulthood. Understanding of the core features of autism is poor among health professionals and pathways to achieving a diagnosis in adulthood are heterogeneous. Psychiatrists should be equipped with the appropriate knowledge and clinical skills to recognise and assess adults with ASD to ensure accurate diagnosis. It is important to be mindful of the high rates of comorbid medical and psychiatric illnesses and the social and economic disadvantages experienced by this group. Moreover, focused assessment of need and evidence-based treatment planning should inform ongoing follow-up and support. In this way, professionals will ensure that they meet the aspirations of the Autism Strategy, in which:

'adults with autism are able to live fulfilling and rewarding lives within a society that accepts and understands them. They can get a diagnosis and access support if they need it, and they can depend on mainstream public services to treat them fairly as individuals, helping them make the most of their talents' (Department of Health 2010a).

\section{References}

Abdallah MW, Greaves-Lord K, Grove J, et al (2011) Psychiatric comorbidities in autism spectrum disorders: findings from a Danish
Historic Birth Cohort. European Child and Adolescent Psychiatry 20: 599-601.

Allen D, Evans C, Hider A, et al (2008) Offending behaviour in adults with Asperger's Syndrome. Journal of Autism and Developmental Disorders 38: 748-58.

American Psychiatric Association (2004) Diagnostic and Statistical Manual of Mental Disorders (4th edn, text rev) (DSM-IV-TR). APA

American Psychiatric Association (2013) Diagnostic and Statistical Manual of Mental Disorders (5th edn) (DSM-5). APA.

Arnold LE, Aman MG, Cook AM, et al (2006) Atomoxetine for hyperactivity in autism spectrum disorders: placebo controlled crossover pilot trial. Journal of the American Academy of Child and Adolescent Psychiatry 45: 1196-205.

Bailey A, Luthert P, Dean A, et al (1998) A clinicopathological study of autism. Brain 121: 889-905

Baird G, Simonoff E, Pickles A, et al (2006) Prevalence of disorders of the autism spectrum in a population cohort of children in South Thames: the Special Needs and Autism Project (SNAP). Lancet 368: 210-5.

Bancroft C, Batten A, Lambert S, et al (2012) The Way We Are: Autism in 2012. National Autistic Society.

Baron-Cohen S, Scahill VL, Izaguirre J, et al (1999) The prevalence of Gilles de la Tourette syndrome in children and adolescents with autism: a large scale study. Psychological Medicine 29: 1151-9.

Baron-Cohen S, Wheelwright S, Skinner R, et al (2001) The AutismSpectrum Quotient ( $A 0)$ : evidence from Asperger syndrome/highfunctioning autism, males and females, scientists and mathematicians. Journal of Autism and Developmental Disorders 31: 5-17.

Bejerot S, Nylande L, Lindstrom E (2001) Autistic traits in obsessive compulsive disorder. Nordic Journal of Psychiatry 55: 169-76.

Bejerot S, Nylander L (2003) Low prevalence of smoking in patients with autism spectrum disorders. Psychiatry Research 119: 177-82.

Berney T, Brugha T, Carpenter P (2011) Royal College of Psychiatrists Diagnostic Interview Guide for the Assessment of Adults with Autism Spectrum Disorder (ASD). Royal College of Psychiatrists, College Education and Training Centre

Bishop SL, Seltzer MM (2012) Self-reported autism symptoms in adults with autism spectrum disorders. Journal of Autism and Developmental Disorders 42: 2354-61.

Bloeman OJN, Deeley 0, Sundram F, et al (2010) White matter integrity in Asperger syndrome: a preliminary diffusion tensor magnetic resonance imaging study in adults. Autism Research 3: 203-13.

Browning A, Caulfield $L$ (2011) The prevalence and treatment of people with Asperger's syndrome in the criminal justice system. Criminology and Criminal Justice 11: 165-78.

Brugha ST, McManus S, Bankart J, et al (2011) Epidemiology of autism spectrum disorders in adults in the community in England. Archives of General Psychiatry 65: 459-65.

Butler MG, Dasouki MJ, Zhou XP, et al (2005) Subset of individuals with autism spectrum disorders and extreme macrocephaly associated with germline PTEN tumour suppressor gene mutations. Journal of Medical Genetics 42: 318-21.

Caglayan AO (2010) Genetic causes of syndromic and non-syndromic autism. Developmental Medicine and Child Neurology 52: 130-8.

Chaplin E, Gilvarry C, Tsakanikos E (2011) Recreational substance use patterns and co-morbid psychopathology in adults with intellectual disability. Research in Developmental Disabilities 32: 2981-6.

Danielsson S, Gillberg C, Billstedt E, et al (2005) Epilepsy in young adults with autism: a prospective population based follow-up study of 120 individuals diagnosed in childhood. Epilepsia 46: 918-23.

Department of Health (2010a) Fulfilling and Rewarding Lives: The Strategy for Adults with Autism in England. Department of Health

Department of Health (2010b) Prioritising Need in the Context of Putting People First: A Whole System Approach to Eligibility for Social Care - Guidance on Eligibility Criteria for Adult Social Care, England 2010. Department of Health. 


\section{MCO answers \\ 1 a 2 a 3 e 4 c 5 e}

Eaves LC, Ho HH (2008) Young adult outcome of autism spectrum disorders. Journal of Autism and Developmental Disorders 38: 739-47.

Ecker C, Marquand A, Mourao-Miranda J, et al (2010) Describing the brain in autism in five dimensions - magnetic resonance imagingassisted diagnosis of autism spectrum disorder using a multiparameter classification approach. Journal of Neuroscience 30: 10612-23.

Esbensen AJ, Greenberg JS, Seltzer MM, et al (2009) A longitudinal investigation of psychotropic and non-psychotropic medication use among adolescents and adults with autism spectrum disorders. Journal of Autism and Developmental Disorders 39: 1339-49.

Fitzgerald M, Corvin A (2001) Diagnosis and differential diagnosis of Asperger syndrome. Advances in Psychiatric Treatment 7: 310-8.

Garcia-Villamisar DA, Dattilo J (2010) Effects of a leisure programme on quality of life and stress of individuals with ASD. Journal of Intellectual Disability Research 54: 611-9.

Ghaziuddin M, Ghaziuddin N, Greden J (2002) Depression in persons with autism: implications for research and clinical care. Journal of Autism and Developmental Disorders 32: 299-306.

Gillberg C, Billstedt E (2000) Autism and Asperger syndrome: coexistence with other clinical disorders. Acta Psychiatrica Scandinavica 102: 321-30.

Graetz JE (2010) Autism grows up: opportunities for adults with autism. Disability and Society 25: 33-47.

Grayton HM, Fernandes C, Rujescu D, et al (2012) Copy number variations in neurodevelopmental disorders. Progress in Neurobiology 99: 81-91.

Hall HR, Graff JC (2011) The relationships among adaptive behaviours of children with autism, family support, parenting stress, and coping. Issues in Comprehensive Paediatric Nursing 34: 4-25.

Hafterkamp M, van de Loo-Neus G, Minderaa RB, et al (2012) A randomised controlled trial of atomoxetine versus placebo for attentiondeficit/hyperactivity disorder symptoms in children with autism spectrum disorder. Journal of the American Academy of Child and Adolescent Psychiatry 51: 733-41.

Heidgerken AD, Geffken G, Modi A, et al (2005) A survey of autism knowledge in a health care setting. Journal of Autism and Developmental Disorders 35: 323-30.

Hellings JA, Zarcone JR, Reese RM, et al (2006) A crossover study of risperidone in children, adolescents and adults with mental retardation. Journal of Autism and Developmental Disorders 36: 401-11.

Higgins KK, Koch LC, Boughfman EM, et al (2008) School-to-work transition and Asperger syndrome. Work 31: 291-8.

Hofvander B, Delorme R, Chaste P, et al (2009) Psychiatric and psychosocial problems in adults with normal-intelligence autism spectrum disorders. BMC Psychiatry 9: 35

Howlin P, Asgharian A (1999) The diagnosis of autism and Asperger syndrome: findings from a survey of 770 families. Developmental Medicine and Child Neurology 41: 834-9.

Howlin P, Goode S, Hutton J, et al (2004) Adult outcome for children with autism. Journal of Child Psychology and Psychiatry 45: 212-29.

Howlin P, Moss P (2012) Adults with autism spectrum disorders. Canadian Journal of Psychiatry 57: 275-83.

Joshi G, Wozniak J, Petty C, et al (2013) Psychiatric comorbidity and functioning in a clinically referred population of adults with autism spectrum disorders: a comparative study. Journal of Autism and Developmental Disorders 43: 1314-25.

Kalyva $\mathrm{E}$ (2009) Comparison of eating attitudes between adolescent girls with and without Asperger syndrome: daughters' and mothers' reports. Journal of Autism and Developmental Disorders 39: 480-6.

Kana R, Wadsworth $H$ (2012) The archeologist's career ended in ruins: hemispheric differences in pun comprehension in autism. Neurolmage 62: 77-86.

Klin A, Saulnier CA, Sparrow SS, et al (2007) Social and communication abilities and disabilities in higher functioning individuals with autism spectrum disorders: the Vineland and the ADOS. Journal of Autism and Developmental Disorders 37: 748-59.
Krakowiak P, Goodlin-Jone B, Hertz-Picciotto I, et al (2008) Sleep problems in children with autism spectrum disorders, developmental delays, and typical development: a population-based study. Journal of Sleep Research 17: 197-206.

Levisohn P (2007) The autism-epilepsy connection. Epilepsia 48: 33-5. Levy SE, Mandeli DS, Schultz RT (2009) Autism. Lancet 374: 1627-38. Lichtenstein P, Carlstrom E, Rastam M, et al (2010) The genetics of autism spectrum disorders and related neuropsychiatric disorders in childhood. American Journal of Psychiatry 167: 1357-63.

Lord C (1989) Autism Diagnostic Observation Schedule: a standardized observation of communicative and social behaviour. Journal of Autism and Developmental Disorders 19: 185-212.

Lord C, Rutter M, Le Couteur A (1994) Autism Diagnostic Interview Revised: a revised version of a diagnostic interview for caregivers of individuals with possible pervasive developmental disorders. Journal of Autism and Developmental Disorders 24: 659-85.

Lord C, Risi S, Lambrecht L, et al (2000) The Autism Diagnostic Observation Schedule-Generic: a standard measure of social and communication deficits associated with the spectrum of autism. Journal of Autism and Developmental Disorders 30: 205-23.

Lotter V (1996) Epidemiology of autistic conditions in young children. Social Psychiatry and Psychiatric Epidemiology 1: 124-35.

Lugnegard T, Hallerback MU, Gillberg C (2011) Psychiatric comorbidity in young adults with a clinical diagnosis of Asperger syndrome. Research in Developmental Disabilities 32: 1910-7.

Mandelstam M (2011) Safeguarding Adults at Risk of Harm: A Legal Guide for Practitioners. Social Care Institute for Excellence.

Marcus RN, Owen R, Kamen L, et al (2009) A placebo-controlled, fixeddose study of aripiprazole in children and adolescents with irritability associated with autistic disorder. Journal of the American Academy of Child and Adolescent Psychiatry 48: 1110-9.

Matson JL, Nebel-Schwalm MS (2007) Comorbid psychopathology with autism spectrum disorder in children: an overview. Research in Developmental Disabilities 28: 341-53.

Matson JL, Shoemaker M (2009) Intellectual disability and its relationship to autism spectrum disorders. Research in Developmental Disabilities 30 : 1107-14.

McDougle CJ, Kresch LE, Goodman WK, et al (1995) A case controlled study of repetitive behaviour in adults with autistic disorder and obsessive compulsive disorder. American Journal of Psychiatry 152: 772-7.

McDougle CJ, Naylor ST, Cohen DJ, et al (1996) A double- blind, placebocontrolled study of fluvoxamine in adults with autistic disorder. Archives of General Psychiatry 53: 1001-8.

McDougle CJ, Holmes JP, Carlson DC, et al (1998) A double-blind, placebo-controlled study of risperidone in adults with autistic disorder and other pervasive developmental disorders. Archives of General Psychiatry 55: 633-41.

Molloy CA, Manning-Courtney P (2003) Prevalence of chronic gastrointestinal symptoms in children with autism and autistic spectrum disorders. Autism 7: 165-71.

Mouridsen SE, Bronnum-Hansen H, Rich B, et al (2008) Mortality and causes of death in autism spectrum disorders: an update. Autism 12: 403-14.

National Audit Office (2009) Supporting People with Autism through Adulthood. NAO.

National Institute for Health and Clinical Excellence (2012) Autism: Recognition, Referral, Diagnosis and Management of Adults on The Autism Spectrum (Clinical Guideline CG142). NICE.

National Institute for Health Research (2012) AQ-10: Autism Spectrum Quotient ( $A Q)$. Autism Research Centre/University of Cambridge.

Oliveira G, Ataide A, Marques C, et al (2007) Epidemiology of autism spectrum disorder in Portugal: prevalence, clinical characterization, and medical conditions. Developmental Medicine \& Child Neurology 49 : 726-33. 
Owen R, Sikich L, Marcus RN, et al (2009) Aripiprazole in the treatment of irritability in children and adolescents with autistic disorder. Pediatrics 124: $1533-40$.

Pickett J, Xiu E, Tuchman R, et al (2011) Mortality in individuals with autism, with and without epilepsy. Journal of Child Neurology 26: 232-9.

Raja M, Azzonni A (2010) Autistic spectrum disorders and schizophrenia in the adult psychiatric setting: diagnosis and comorbidity. Psychiatria Danubina 22: 514-21.

Research Units on Paediatric Psychopharmacology (2005) Randomized, controlled, crossover trial of methylphenidate in pervasive developmental disorders with hyperactivity. Archives of General Psychiatry 62: 1266-74.

Royal College of Psychiatrists (2001) DC-LD: Diagnostic Criteria for Psychiatric Disorders for Use with Adults with Learning Disabilities/ Mental Retardation (Occasional Paper OP48). Gaskell.

Royal College of Psychiatrists (2006) Psychiatric Services for Adolescents and Adults with Asperger Syndrome and Other Autistic-spectrum Disorders (Council Report CR136). Royal College of Psychiatrists.

Rutter M (1978) Diagnosis and Definition. Autism: A Reappraisal of Concepts and Treatment. Plenum Press.

Rutter M, Bailey A, Bolton P, et al (1994) Autism and known medical conditions: myth and substance. Journal of Child Psychology and Psychiatry 35: 311-22

Santosh PJ, Mijovic A (2006) Does pervasive developmental disorder protect children and adolescents against drug and alcohol use? European Child and Adolescent Psychiatry 15: 183-6.

Schneider FR, Johnson J, Hornig CD, et al (1992) Social phobia: comorbidity and morbidity in an epidemiologic sample. Archives of General Psychiatry 49: 282-8.

Scragg P, Shah A (1994) Prevalence of Asperger's syndrome in a secure hospital. British Journal of Psychiatry 165: 679-82.

Shattuck PT, Narendorf SC, Cooper B, et al (2012) Post secondary education and employment among youth with an autism spectrum disorder. Pediatrics 129: 1042-9.

Sheitman BB, Kraus JE, Bodfish JW, et al (2004) Are the negative symptoms of schizophrenia consistent with an autistic spectrum illness? Schizophrenia Research 69: 119-20.

Sizoo B, van de Brink W, Koeter M, et al (2010) Treatment seeking adults with autism or ADHD and co-morbid substance use disorder: prevalence, risk factors and functional disability. Drug and Alcohol Dependence 107: 44-50.

Skokauskas N, Gallagher L (2010) Psychosis, affective disorders and anxiety in autistic spectrum disorder: prevalence and nosological considerations. Psychopathology 43: 8-16

Smith KRM, Matson JL (2010) Social skills: differences among adults with intellectual disabilities, co-morbid autism spectrum disorders and epilepsy. Research in Developmental Disabilities 21: 1366-72.
Social Care Institute for Excellence (2011a) At a glance 21. Personalisation Briefing: Implications for People with autistic Spectrum Conditions and Their Family Carers. SCIE.

Social Care Institute for Excellence (2011b) Improving Access to Social Care for Adults with Autism (SCIE Guide 43). SCIE.

Treasure J, Claudino AM, Zucker N (2010) Eating disorders. Lancet 375 $583-93$

Tsiouris JA, Kim SY, Brown WT, et al (2013) Prevalence of psychotropic drug use in adults with intellectual disability: positive and negative findings from a large scale study. Journal of Autism and Developmental Disorders 43: 719-31.

Tuchman R, Rapin M (2011) Epilepsy in autism: neurodevelopmental perspective. Current Neurology and Neuroscience Reports 11: 428-34.

Venkat A, Jauch E, Russel WS, et al (2012) Care of the patient with an autism spectrum disorder by the general physician. Postgraduate Medical Journal 88: 472-81.

Volkmar FR, Cohen DJ (1998) Comorbid association of autism and schizophrenia. American Journal of Psychiatry 148: 1705-7.

Waris P, Lindberg N, Kettunen K, et al (2013) The relationship between Asperger's syndrome and schizophrenia in adolescence. European Child and Adolescent Psychiatry 22: 217-23.

Wentz E, Lacey JH, Waller G, et al (2005) Childhood onset neuropsychiatric disorders in adult eating disorder patients: a pilot study. European Child and Adolescent Psychiatry 14: 43-37.

White SW, Roberson-Nay R (2009) Anxiety, social deficits, and loneliness in youth with autism spectrum disorders. Journal of Autism and Developmental Disorders 39: 1006-13.

White SW, Bray BC, Ollendick TH (2012) Examining shared and unique aspects of social anxiety disorder and autism spectrum disorder using factor analysis. Journal of Autism and Developmental Disorders 42: 874-84.

Wing L, Gould J (1979) Severe impairments of social interaction and associated abnormalities in children: epidemiology and classification. Journal of Autism and Childhood Schizophrenia 9. 11-29.

Wing L, Potter G (2002) The epidemiology of autistic spectrum disorders: is the prevalence rising? Mental Retardation and Developmental Disabilities Research Reviews 8: 151-61.

Woodbury-Smith MR, Robinson J, Wheelwright S, et al (2005) Screening adults for Asperger syndrome using the $\mathrm{A} 0$ : a preliminary study of its diagnostic validity in clinical practice. Journal of Autism and Developmental Disorders 35: 331-5.

World Health Organization (1992) The ICD-10 Classification of Mental and Behavioural Disorders: Clinical Descriptions and Diagnostic Guidelines (ICD-10). WHO.

\section{MCQs}

Select the single best option for each question stem

1 The ICD-10 states that a core diagnostic criterion for autism is:

a qualitative impairment in reciprocal social interaction

b emotionally determined selectivity in verbal communication

c repetitive circumscribed movements

d abnormal development after the age of 3 years

e the presence of challenging behaviour.

\section{Clinical features not typically associated} with Asperger syndrome include:

a language delay

b normal 10 c difficulty in social interaction

d impairment in communication

e restricted and repetitive patterns of behaviour or interests.

3 A comorbid psychiatric illness not commonly associated with ASD is:

a depression

b OCD

c ADHD

d eating disorder

e delusional disorder.

4 Tools used in the assessment of ASD would not usually include:

a ADOS-G b ADI-R

c ACE-R

d $A 0$

e SCO.

5 Which of the following treatments is recommended in the management of adults with $A S D$ ?

a facilitated communication

b antidepressants for repetitive behaviours

c elimination diets

d antipsychotics for core autistic features

e social skills training. 